\title{
AN UNSTEADY ANALYSIS OF NONLINEAR TWO-LAYERED 2D MODEL OF PULSATILE FLOW THROUGH STENOSED ARTERIES ${ }^{1}$
}

\author{
P.K. MANDAL \\ Department of Mathematics, Krishnath College \\ P.O.-Berhampore, W.B. 742 101, INDIA \\ E-mail: pkmind02@yahoo.co.uk \\ Received December 10, 2002; revised May 4, 2003
}

\begin{abstract}
The effects of red cell concentration and peripheral layer viscosity on physiological characteristics of pulsatile flow in presence of mild stenosis are investigated. The flowing blood is represented by a two-fluid model, consisting of a core region of suspension of all the erythrocytes assumed to be non-Newtonian (inhomogeneous Newtonian) and a peripheral plasma layer free from cells of any kind as a Newtonian fluid. In the realm of the flow characteristics of blood the viscosity is taken to be a function of hematocrit in a manner that it varies radially only in the central core characterising its non-Newtonian behaviour while it remains constant in the plasma region. The arterial wall motion and its effect on local fluid mechanics is also incorporated in the present theoretical study. Finite difference scheme has been used to solve the unsteady Navier-Stokes equations in cylindrical coordinates assuming axial symmetry under laminar conditions, so that the problem effectively becomes two-dimensional. The nonlinear terms appearing in the Navier-Stokes equations governing blood flow are accounted for. Finally, the numerical illustration presented at the end of the paper provides an effective measure of the flux, the resistive impedance and the wall shear stress quantitatively in order to validate the applicability of the present model.
\end{abstract}

Key words: Hematocrit, Stenosis, Inhomogeneous Newtonian, Resistive impedance, Wall shear stress

\section{INTRODUCTION}

The studies related to blood flow have long occupied the attention of the researchers - both the theoretical modellers and the experimentalists in general,

\footnotetext{
${ }^{1}$ The author would like to thank the referees for careful reading for the manuscript and for helpful suggestions. The author gratefully acknowledges Professor S. Chakravarty, Department of Mathematics, Visva-Bharati, INDIA for his valuable suggestions while preparing the manuscript.
} 
and to the stenosed blood flow, in particular. Although the exact mechanism responsible for the initiation of the depositions of blood cells and lipids, a leading cause of stenosis are not clearly known, it has been established that once a mild stenosis is developed, the resulting flow disorder plays an important role in the further development of the disease (Misra and Chakravarty [16]; Deplano and Siouffi [9]; Chakravarty and Mandal [7]; Anderson et al [1]; Long et al [14]). Under normal physiological condition, the transport of blood in the human circulatory system depends entirely on the pumping action of the heart producing a pulsatile pressure gradient throughout the arterial system and on the haematocrit.

Most of the studies referred to above have been carried out with the assumption that blood behaves like a Newtonian fluid. It has now been well accepted that blood, being a suspension of cells, behaves like a non-Newtonian fluid at low shear rates in smaller arteries under certain flow conditions (cf. Chaturani and Samy [8]; Nakamura and Swada [18]; Chakravarty and Datta [5]; Misra et al [17]; Tu and Deville [28]; Liepsch et al[13]). Some researchers (Bugliarello and Sevilla [3], Thurston [27]) have shown that for blood flowing through small vessels there is an erythrocyte-free plasma (Newtonian) layer adjacent to the vessel wall and a core layer of suspension of all the erythrocytes (nonNewtonian). Accepting this idea, several studies (Shukla et al [21]; Pralhad and Schultz [20]; Srivastava and Saxena [24]; Srivastava [23]) revealed that the existence of the peripheral layer would be of some significance in functioning of the diseased arterial system. These studies were based on the use of the linearized Navier-Stokes equations which may suit well for explaining some aspects of haemodynamic flow in smaller arteries, but for larger arteries, consideration of the nonlinear terms in the Navier-Stokes equations governing the flow of blood becomes indispensable. These terms may be disregarded in a one-dimensional blood flow hypothesis but for two-dimensional flow in larger arteries they are of major significance having large dynamic storage effects. Moreover, in most of the recent literatures relevant to constricted flow either in a rigid artery or in a flexible one, the stenotic geometry has been largely regarded as time-independent. Such consideration may suit well for a rigid vessel at the steady state condition but for a flexible artery, the stenosis can neither remain static at the unsteady state nor even at the steady state situation. Therefore, for a realistic description of blood flow in a stenosed artery, perhaps it would be most appropriate to treat blood as a two-fluid model consisting of a central core region containing all the erythrocytes assumed to be a non-Newtonian fluid and a peripheral layer of plasma as a Newtonian fluid while the vessel is treated as a deformable one. An improved problem such as this should include the two-dimensional flow characteristics of blood in order to have a complete understanding of the flow disorder in the presence of stenosis.

With the above considerations in mind, a good attempt is made in the present theoretical study to examine some of the significant characteristics of the nonlinear blood flow through a stenosed flexible artery under a pulsatile 
pressure gradient. The arterial segment is treated to be a cylindrical tube containing a nonhomogeneous fluid representing blood. Blood is assumed to be a two-fluid model consisting of a central core region characterized to be a non-Newtonian fluid and a peripheral layer of plasma as a Newtonian fluid. The functional dependence of blood viscosity on hematocrit has been duly accounted for in order to improve resemblance to the real situation. Although the general problem such as the present one is of major physiological significance, the attention is paid to the effect of wall motion on local fluid mechanics but not on the stresses and strains in the arterial wall. The consideration of a time-variant geometry of the stenosis has not however been ruled out in the present analysis. An extensive quantitative analysis is carried out by performing large scale numerical computations of the quantities having major physiological significance and presented graphically at the end of the paper with adequate discussions so as to justify the applicability of the improved model under study.

\section{FORMULATION OF THE PROBLEM}

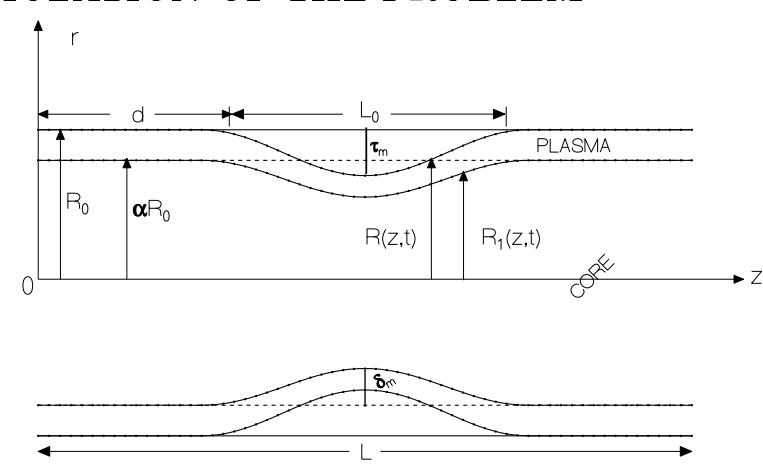

Figure 1. Geometry of the arterial stenosis with peripheral layer.

The constricted arterial segment is modelled as a thin cylindrical tube containing a nonhomogeneous fluid, consisting of a central core region characterized to be non-Newtonian and a peripheral layer of plasma as a Newtonian fluid, representing blood. Let $(r, \theta, z)$ be the coordinates of a material point in the cylindrical polar coordinates system where the $z$-axis is taken along the axis of the artery while $r, \theta$ are taken along the radial and the circumferential directions respectively. The geometry of the time-variant stenosis (cf. Fig. 1) is described mathematically as (Shukla et al [21], Young[10])

$$
\frac{\left(R, R_{1}\right)(z, t)}{R_{0}}=\left\{\begin{array}{c}
{\left[(1, \alpha)-\frac{\left(\tau_{m}, \delta_{m}\right)}{2 R_{0}}\left\{1+\cos \frac{2 \pi}{L_{0}}\left(z-d-\frac{L_{0}}{2}\right)\right\}\right] a_{1}(t)} \\
\quad d \leq z \leq d+L_{0} \\
(1, \alpha) a_{1}(t), \quad \text { otherwise }
\end{array}\right.
$$


where $R(z, t)$ is the radius of the arterial segment in the constricted region, $R_{0}$ the constant radius of the normal artery in the non-constricted region, $L_{0}$ the length of the stenosis, $d$ the location of the stenosis and $\left(\tau_{m}, \delta_{m}\right)$ are the maximum height of the stenosis and bulging of interface respectively appearing at $z=d+L_{0} / 2$ where $\delta_{m}=\alpha \tau_{m}$. The limitation of the present mild stenosis $\left(\frac{\tau_{m}}{R_{0}}<<1\right)$ has been briefly discussed by Srivastava [22]. Here $R_{1}(z, t)$ is chosen to be the radius of the core fluid layer and a peripheral plasma layer of thickness $\left(R-R_{1}\right)$ as shown in Fig. 1 . The time-variant parameter $a_{1}(t)$ is given by

$$
a_{1}(t)=1-b(\cos \omega t-1) e^{-b \omega t},
$$

in which $\omega$ represents the angular frequency and $b$ is a constant. The arterial segment is taken to be of finite length $L$.

Let us consider the stenotic blood flow in the artery to be nonlinear, unsteady, axisymmetric, two-dimensional and fully developed, where the flowing blood is treated to be composed of a non-Newtonian core fluid and a Newtonian peripheral plasma fluid. The appropriate equations describing such a two-fluid flow, in the cylindrical coordinate system may be written as

$$
\begin{aligned}
& \frac{\partial w_{i}}{\partial t}+u_{i} \frac{\partial w_{i}}{\partial r}+w_{i} \frac{\partial w_{i}}{\partial z}=-\frac{1}{\rho} \frac{\partial p}{\partial z}+\frac{\mu(r)}{\rho}\left(\frac{\partial^{2} w_{i}}{\partial r^{2}}+\frac{1}{r} \frac{\partial w_{i}}{\partial r}+\frac{\partial^{2} w_{i}}{\partial z^{2}}\right) \\
& \frac{\partial u_{i}}{\partial t}+u_{i} \frac{\partial u_{i}}{\partial r}+w_{i} \frac{\partial u_{i}}{\partial z}=-\frac{1}{\rho} \frac{\partial p}{\partial r}+\frac{\mu(r)}{\rho}\left(\frac{\partial^{2} u_{i}}{\partial r^{2}}+\frac{1}{r} \frac{\partial u_{i}}{\partial r}+\frac{\partial^{2} u_{i}}{\partial z^{2}}-\frac{u_{i}}{r^{2}}\right) \\
& \frac{\partial u_{i}}{\partial r}+\frac{u_{i}}{r}+\frac{\partial w_{i}}{\partial z}=0
\end{aligned}
$$

where $u_{i}$ and $w_{i}(i=1,2)$ are the radial and the axial velocity components respectively, $\mu(r)$ represents the viscosity of blood in the central core region for $0 \leq r \leq R_{1}(z, t)$ and that of the plasma region for $R_{1}(z, t) \leq r \leq R(z, t)$, $p$ is the pressure and $\rho$, the density of blood. Here and in the sequel, $i=1$ corresponds to the central core region $\left(0 \leq r \leq R_{1}(z, t)\right)$ and the plasma region $\left(R_{1}(z, t) \leq r \leq R(z, t)\right)$ is designated by $i=2$.

Since the lumen radius, $R$, is sufficiently smaller than the wavelength $\lambda$, of the pressure wave i.e. $\frac{R}{\lambda}<<1$, the radial Navier-Stokes equation simply reduces to $\frac{\partial p}{\partial r}=0$ (Pedley [19]) and hence equation (2.4) can be omitted. It is then reasonable and convenient to assume that the pressure is independent of radial coordinate (Imaeda and Goodman [12]) and eventually the pressure gradient $\frac{\partial p}{\partial z}$ appearing in (2.3), whose form has been taken for human beings (Burton [4]) as

$$
-\frac{\partial p}{\partial z}=A_{0}+A_{1} \cos \omega t
$$

where $A_{0}$ is the constant amplitude of the pressure gradient, $A_{1}$ is the amplitude of the pulsatile component giving rise to systolic and diastolic pressure; $\omega=2 \pi f_{p}, f_{p}$ being the pulse frequency. 


\section{BOUNDARY CONDITIONS}

In the central core region, there is no radial flow along the axis and the axial velocity gradient of the core flow along the axis may be assumed to be equal to zero. These may be stated mathematically as

$$
\begin{cases}u_{1}(r, z, t)=0 & \text { on } r=0 \\ \frac{\partial w_{1}(r, z, t)}{\partial r}=0 & \text { on } r=0 .\end{cases}
$$

At the interface between the central core and the peripheral plasma layer of the fluid media, the velocities and the stresses are assumed to be continuous which may be written mathematically as

$$
\begin{cases}w_{1}(r, z, t)=w_{2}(r, z, t) & \text { on } \quad r=R_{1}(z, t), \\ u_{1}(r, z, t)=u_{2}(r, z, t) & \text { on } \quad r=R_{1}(z, t), \\ \left(\tau_{r z}\right)_{1}=\left(\tau_{r z}\right)_{2} & \text { on } \quad r=R_{1}(z, t) .\end{cases}
$$

Also, the velocity boundary conditions on the arterial wall are taken as

$$
\left\{\begin{array}{l}
u_{2}(r, z, t)=\frac{\partial R}{\partial t}, \quad \text { on } r=R(z, t), \\
w_{2}(r, z, t)=0 \text { on } r=R(z, t)
\end{array}\right.
$$

It is further assumed that initially no flow takes place when the system is at rest, that means

$$
u_{i}(r, z, 0)=0, w_{i}(r, z, 0)=0, \quad i=1,2 .
$$

\section{METHOD OF SOLUTION}

Let us introduce a radial coordinate transformation, given by

$$
\xi=\frac{r}{R(z, t)}
$$

which has the effect of immobilizing the vessel wall in the transformed coordinate $\xi$. Using this transformation, the equations (2.3) and (2.5) representing 
blood flow and the prescribed conditions (3.1) - (3.4) take the following form

$$
\begin{gathered}
\frac{\partial w_{i}}{\partial t}=-\frac{1}{\rho} \frac{\partial p}{\partial z}+\left[\xi R \frac{\partial R}{\partial t}+\frac{\mu(\xi)}{\rho \xi}-\frac{\mu(\xi)}{\rho}\left\{\xi R \frac{\partial^{2} R}{\partial z^{2}}-2 \xi\left(\frac{\partial R}{\partial z}\right)^{2}\right\}\right] \frac{1}{R^{2}} \frac{\partial w_{i}}{\partial \xi} \\
+\frac{\mu(\xi)}{\rho R^{2}}\left[1+\left(\xi \frac{\partial R}{\partial z}\right)^{2}\right] \frac{\partial^{2} w_{i}}{\partial \xi^{2}}-\frac{u_{i}}{R} \frac{\partial w_{i}}{\partial \xi}-w_{i}\left(\frac{\partial w_{i}}{\partial z}-\frac{\xi}{R} \frac{\partial R}{\partial z} \frac{\partial w_{i}}{\partial \xi}\right) \\
+\frac{\mu(\xi)}{\rho} \frac{\partial^{2} w_{i}}{\partial z^{2}}, \\
\frac{1}{R} \frac{\partial u_{i}}{\partial \xi}+\frac{u_{i}}{\xi R}+\frac{\partial w_{i}}{\partial z}-\frac{\xi}{R} \frac{\partial R}{\partial z} \frac{\partial w_{i}}{\partial \xi}=0, i=1,2 \\
\left.u_{1}(\xi, z, t)\right|_{\xi=0}=0,\left.\quad \frac{\partial w_{1}(\xi, z, t)}{\partial \xi}\right|_{\xi=0}=0 \\
\left\{\begin{array}{l}
w_{1}(\xi, z, t)=w_{2}(\xi, z, t) \text { on } \xi=\alpha \\
u_{1}(\xi, z, t)=u_{2}(\xi, z, t) \text { on } \xi=\alpha \\
\left(\tau_{\xi z}\right)_{1}=\left(\tau_{\xi z}\right)_{2} \text { on } \xi=\alpha \\
u_{2}(\xi, z, t)=\frac{\partial R}{\partial t}, \quad w_{2}(\xi, z, t)=0 \text { on } \xi=1
\end{array}\right.
\end{gathered}
$$

and

$$
u_{i}(\xi, z, 0)=0, \quad w_{i}(\xi, z, 0)=0, \quad i=1,2 .
$$

Here, the central core region corresponding to $i=1$ is represented by $0 \leq \xi \leq$ $\alpha$ while the peripheral plasma layer corresponding to $i=2$ is designated by $\alpha \leq \xi \leq 1$ in the transformed domain.

For the core region $(0 \leq \xi \leq \alpha)$, multiplying (4.3) by $\xi R$ and integrating with respect to $\xi$ from the limits 0 to $\xi(0 \leq \xi \leq \alpha)$ one finds,

$$
u_{1}(\xi, z, t)=\frac{\partial R}{\partial z}\left[\xi w_{1}-\frac{2}{\xi} \int_{0}^{\xi} \phi w_{1} d \phi\right]-\frac{R}{\xi} \int_{0}^{\xi} \phi \frac{\partial w_{1}}{\partial z} d \phi
$$

This equation takes the following form by making use of the boundary conditions (4.5) as

$$
\int_{0}^{\alpha} \xi \frac{\partial w_{1}}{\partial z} d \xi=\int_{0}^{\alpha} \xi\left[-\frac{2}{R} \frac{\partial R}{\partial z} w_{1}+\frac{\alpha}{R}\left(\alpha \frac{\partial R}{\partial z} w_{1 \alpha}-u_{1 \alpha}\right) f(\xi)\right] d \xi
$$


where

$$
\begin{aligned}
& w_{1 \alpha}=\left.w_{1}(\xi, z, t)\right|_{\xi=\alpha}=\left.w_{2}(\xi, z, t)\right|_{\xi=\alpha} \\
& u_{1 \alpha}=\left.u_{1}(\xi, z, t)\right|_{\xi=\alpha}=\left.u_{2}(\xi, z, t)\right|_{\xi=\alpha}
\end{aligned}
$$

Since the choice of $f(\xi)$ is, of course, arbitrary, let $f(\xi)$ be of the form

$$
f(\xi)=\frac{4\left(\xi^{2}-1\right)}{\alpha^{2}\left(\alpha^{2}-2\right)}
$$

satisfying

$$
\int_{0}^{\alpha} \xi f(\xi) d \xi=1
$$

Taking the approximation of considering the equality between the integrals to integrands, we have from (4.9)

$$
\frac{\partial w_{1}}{\partial z}=-\frac{2}{R} \frac{\partial R}{\partial z} w_{1}+\frac{\alpha}{R}\left(\alpha \frac{\partial R}{\partial z} w_{1 \alpha}-u_{1 \alpha}\right) \frac{4\left(\xi^{2}-1\right)}{\alpha^{2}\left(\alpha^{2}-2\right)} .
$$

Substituting (4.10) into (4.8) one finds

$$
u_{1}(\xi, z, t)=\xi\left[\frac{\partial R}{\partial z} w_{1}-\frac{\alpha \frac{\partial R}{\partial z} w_{1 \alpha}-u_{1 \alpha}}{\alpha\left(\alpha^{2}-2\right)}\left(\xi^{2}-2\right)\right] .
$$

In a similar manner, for the plasma region $(\alpha \leq \xi \leq 1)$, multiplying (4.3) by $\xi R$ and integrating with respect to $\xi$ from the limits $\alpha$ to $\xi(\alpha \leq \xi \leq 1)$ and exploiting the boundary conditions (4.6), one finds (to save space, detailed derivations are not given here)

$$
\begin{aligned}
u_{2}(\xi, z, t)= & \xi\left[\frac{\partial R}{\partial z} w_{2}+\frac{1}{\xi^{2}}\left(\alpha u_{2 \alpha}-\alpha^{2} \frac{\partial R}{\partial z} w_{2 \alpha}-\frac{\partial R}{\partial t}\right)\right. \\
& \left.\times \frac{\left(\xi^{2}-\alpha^{2}\right)\left(\xi^{2}+\alpha^{2}-2\right)}{\left(\alpha^{2}-1\right)^{2}}+\frac{\alpha}{\xi^{2}}\left(u_{2 \alpha}-\alpha \frac{\partial R}{\partial z} w_{2 \alpha}\right)\right]
\end{aligned}
$$

Again, $u_{1 \alpha}\left(=u_{2 \alpha}\right)$ appearing in equations (4.11) and (4.12) can be obtained, just by putting $\xi=\alpha$, from

$$
u_{2}(\xi, z, t)=\frac{\xi^{2}+1}{2 \xi}\left[\frac{\partial R}{\partial z} w_{2}-\frac{R}{2} \frac{\xi^{2}-1}{\xi^{2}+1} \frac{\partial w_{2}}{\partial z}+\frac{2}{\xi^{2}+1} \frac{\partial R}{\partial t}\right]
$$


which is another form of equation (4.12). By making use of (4.11), equation (4.2) takes the form

$$
\begin{aligned}
\frac{\partial w_{1}}{\partial t}=-\frac{1}{\rho} \frac{\partial p}{\partial z}+T_{1}(\xi, z, t) \frac{\partial w_{1}}{\partial \xi} & +T_{2}(\xi, z, t) \frac{\partial^{2} w_{1}}{\partial \xi^{2}}-w_{1} \frac{\partial w_{1}}{\partial z} \\
& +\frac{\mu(\xi)}{\rho} \frac{\partial^{2} w_{1}}{\partial z^{2}}, \quad 0 \leq \xi \leq \alpha
\end{aligned}
$$

and from (4.12) and (4.2), one must have

$$
\begin{aligned}
\frac{\partial w_{2}}{\partial t}=-\frac{1}{\rho} \frac{\partial p}{\partial z}+T_{3}(\xi, z, t) \frac{\partial w_{2}}{\partial \xi} & +T_{2}(\xi, z, t) \frac{\partial^{2} w_{2}}{\partial \xi^{2}}-w_{2} \frac{\partial w_{2}}{\partial z} \\
& +\frac{\mu(\xi)}{\rho} \frac{\partial^{2} w_{2}}{\partial z^{2}}, \quad \alpha \leq \xi \leq 1,
\end{aligned}
$$

where

$$
\left\{\begin{aligned}
T_{1}(\xi, z, t)= & {\left[\xi R \frac{\partial R}{\partial t}+\frac{\mu(\xi)}{\rho \xi}-\frac{\mu(\xi)}{\rho}\left\{\xi R \frac{\partial^{2} R}{\partial z^{2}}-2 \xi\left(\frac{\partial R}{\partial z}\right)^{2}\right\}\right.} \\
& \left.+\xi R\left\{\frac{\alpha \frac{\partial R}{\partial z} w_{1 \alpha}-u_{1 \alpha}}{\alpha\left(\alpha^{2}-2\right)}\right\}\left(\xi^{2}-2\right)\right] \frac{1}{R^{2}} \\
T_{2}(\xi, z, t)= & \frac{\mu(\xi)}{\rho R^{2}}\left[1+\left(\xi \frac{\partial R}{\partial z}\right)^{2}\right], \\
T_{3}(\xi, z, t)= & {\left[\xi R \frac{\partial R}{\partial t}+\frac{\mu(\xi)}{\rho \xi}-\frac{\mu(\xi)}{\rho}\left\{\xi R \frac{\partial^{2} R}{\partial z^{2}}-2 \xi\left(\frac{\partial R}{\partial z}\right)^{2}\right\}\right.} \\
& -\frac{R}{\xi}\left\{\alpha u_{2 \alpha}-\alpha^{2} \frac{\partial R}{\partial z} w_{2 \alpha}-\frac{\partial R}{\partial t}\right\} \\
\times & \left.\frac{\left(\xi^{2}-\alpha^{2}\right)\left(\xi^{2}+\alpha^{2}-2\right)}{\left(\alpha^{2}-1\right)^{2}}-\frac{\alpha R}{\xi}\left\{u_{2 \alpha}-\alpha \frac{\partial R}{\partial z} w_{2 \alpha}\right\}\right] \frac{1}{R^{2}}
\end{aligned}\right.
$$

\section{FINITE DIFFERENCE APPROXIMATIONS}

The finite difference scheme for solving Eqs. (4.14) and (4.15) is based on the central difference formula in order to transform all the spatial derivatives in 
the following manner:

$$
\left\{\begin{array}{l}
\frac{\partial w_{m}}{\partial \xi}=\frac{\left(w_{m}\right)_{i, j+1}^{k}-\left(w_{m}\right)_{i, j-1}^{k}}{2 \Delta}=\left(w_{m}\right)_{f \xi}, \\
\frac{\partial^{2} w_{m}}{\partial \xi^{2}}=\frac{\left(w_{m}\right)_{i, j+1}^{k}-2\left(w_{m}\right)_{i, j}^{k}+\left(w_{m}\right)_{i, j-1}^{k}}{(\Delta)^{2}}=\left(w_{m}\right)_{s \xi} \\
\frac{\partial w_{m}}{\partial z}=\frac{\left(w_{m}\right)_{i+1, j}^{k}-\left(w_{m}\right)_{i-1, j}^{k}}{2 \Delta z}=\left(w_{m}\right)_{f z} \\
\frac{\partial^{2} w_{m}}{\partial z^{2}}=\frac{\left(w_{m}\right)_{i+1, j}^{k}-2\left(w_{m}\right)_{i, j}^{k}+\left(w_{m}\right)_{i-1, j}^{k}}{(\Delta z)^{2}}=\left(w_{m}\right)_{s z}
\end{array}\right.
$$

while the time derivatives are transformed by their forward difference approximations given by

$$
\frac{\partial w_{m}}{\partial t}=\frac{\left(w_{m}\right)_{i, j}^{k+1}-\left(w_{m}\right)_{i, j}^{k}}{\Delta t}
$$

where

$$
\Delta= \begin{cases}\Delta \xi & \text { for } m=1 \\ \Delta \xi^{\prime} & \text { for } m=2 .\end{cases}
$$

In a similar manner, we can discretize the derivatives for $u_{m}$, whenever necessary. Here $w_{m}(\xi, z, t)$ is discreatised to $w_{m}\left(\xi_{j}, z_{i}, t_{k}\right)$ and in turn, to $\left(w_{m}\right)_{i, j}^{k}$ where we define $\xi_{j}=(j-1) \Delta \xi,\left(j=1,2, \ldots, N_{c}+1\right)$ such that $\xi_{\left(N_{c}+1\right)}=$ $\alpha$, and $\xi_{j}=\alpha+\left[j-\left(N_{c}+1\right)\right] \Delta \xi^{\prime},\left(j=N_{c}+1, N_{c}+2, \ldots, N+1\right)$ such that $\xi_{(N+1)}=1.0, z_{i}=(i-1) \Delta z,(i=1,2, \ldots, M+1)$ and $t_{k}=(k-1) \Delta t,(k=$ $1,2, \ldots)$ for the entire arterial segment under study with $\Delta \xi, \Delta \xi^{\prime}$ are the increments in the radial direction for the core layer $(0 \leq \xi \leq \alpha)$ and for the plasma layer $(\alpha \leq \xi \leq 1)$ respectively while $\Delta z$ is the increment in the axial direction and $\Delta t$ is the small time increment.

Using (5.1) and (5.2), equations (4.14) and (4.15) may be transformed to the following difference equations:

$$
\begin{aligned}
\left(w_{1}\right)_{i, j}^{k+1}=\left(w_{1}\right)_{i, j}^{k} & +\Delta t\left[-\frac{1}{\rho}\left(\frac{\partial p}{\partial z}\right)^{k}+\left(T_{1}\right)_{i, j}^{k}\left(w_{1}\right)_{f \xi}^{k}+\left(T_{2}\right)_{i, j}^{k}\left(w_{1}\right)_{s \xi}^{k}\right. \\
& \left.-\left(w_{1}\right)_{i, j}^{k}\left(w_{1}\right)_{f z}^{k}+\frac{\mu\left(\xi_{j}\right)}{\rho}\left(w_{1}\right)_{s z}^{k}\right], \quad 0 \leq \xi \leq \alpha \\
\left(w_{2}\right)_{i, j}^{k+1}=\left(w_{2}\right)_{i, j}^{k} & +\Delta t\left[-\frac{1}{\rho}\left(\frac{\partial p}{\partial z}\right)^{k}+\left(T_{3}\right)_{i, j}^{k}\left(w_{2}\right)_{f \xi}^{k}+\left(T_{2}\right)_{i, j}^{k}\left(w_{2}\right)_{s \xi}^{k}\right. \\
& \left.-\left(w_{2}\right)_{i, j}^{k}\left(w_{2}\right)_{f z}^{k}+\frac{\mu\left(\xi_{j}\right)}{\rho}\left(w_{2}\right)_{s z}^{k}\right], \quad \alpha \leq \xi \leq 1
\end{aligned}
$$


where the notations ()$_{i},()_{j}$ and ()$^{k}$ indicate that in the expressions, $z, \xi$ and $t$ are replaced by $z_{i}, \xi_{j}$ and $t_{k}$ respectively wherever they appear and $T_{p}(\xi, z, t)^{\prime} s$ appearing in equation (4.16) are discretised to $T_{p}\left(\xi_{j}, z_{i}, t_{k}\right)$ and in turn, to $\left(T_{p}\right)_{i, j}^{k},(p=1,2,3)$.

Also the prescribed conditions (4.4) - (4.7) together with the initial condition have their finite difference representations, given by

$$
\begin{aligned}
& \left(u_{1}\right)_{i, 1}^{k}=0, \quad\left(w_{1}\right)_{i, 1}^{k}=\left(w_{1}\right)_{i, 2}^{k} \\
& \left(u_{1}\right)_{i, N_{c}+1}^{k}=\left(u_{2}\right)_{i, N_{c}+1}^{k},\left(w_{1}\right)_{i, N_{c}+1}^{k}=\left(w_{2}\right)_{i, N_{c}+1}^{k}, \\
& \left(w_{1}\right)_{i, N_{c}}^{k}=\left(1+\frac{\Delta \xi}{\Delta \xi^{\prime}}\right)\left(w_{2}\right)_{i, N_{c}+1}^{k}-\frac{\Delta \xi}{\Delta \xi^{\prime}}\left(w_{2}\right)_{i, N_{c}+2}^{k} \\
& \left(w_{2}\right)_{i, N+1}^{k}=0, \quad\left(u_{2}\right)_{i, N+1}^{k}=\left(\frac{\partial R}{\partial t}\right)_{i}^{k} \\
& \left(w_{m}\right)_{i, j}^{1}=0, \quad \text { and } \quad\left(u_{m}\right)_{i, j}^{1}=0
\end{aligned}
$$

where the index $N_{c}+1$ corresponds to $\xi=\alpha$.

The difference equations (5.3) and (5.4) are solved for $w_{1}$ and $w_{2}$ by making use of the stated conditions (5.5) - (5.9) throughout the arterial segment under consideration. After having obtained the axial flow velocities for both the central core and the plasma, the radial flow velocity for both the layers (core and plasma) can be calculated from equations (4.11) and (4.12) where $\left(u_{1}\right)_{i, N_{c}+1}$ in equations (4.11) and (4.12) can be determined from equation (4.13).

Now, with the help of the axial and radial flow velocities for both the core and plasma layers, one can easily determine the volumetric flow rate $(Q)$, the resistive impedance $(\lambda)$ and the wall shear stress $(\tau)$ from the following relations, given by

$$
\begin{aligned}
Q_{i}^{k} & =2 \pi\left(R_{i}^{k}\right)^{2}\left[\int_{0}^{\alpha} \xi_{j}\left(w_{1}\right)_{i, j}^{k} d \xi_{j}+\int_{\alpha}^{1} \xi_{j}\left(w_{2}\right)_{i, j}^{k} d \xi_{j}\right], \\
\lambda_{i}^{k} & =\frac{\left|L\left(\frac{\partial p}{\partial z}\right)^{k}\right|}{Q_{i}^{k}} \\
\tau_{i}^{k} & =\mu\left(\xi_{N_{c}+1}\right)\left(\frac{\left(u_{1}\right)_{i+1, N_{c}+1}^{k}-\left(u_{1}\right)_{i-1, N_{c}+1}^{k}}{2 \Delta z}\right. \\
& \left.-\frac{\alpha}{R_{i}^{k}}\left(\frac{\partial R}{\partial z}\right)_{i}^{k} \frac{\left(u_{1}\right)_{i, N_{c}+1}^{k}-\left(u_{1}\right)_{i, N_{c}}^{k}}{\Delta \xi}+\frac{1}{R_{i}^{k}} \frac{\left(w_{1}\right)_{i, N_{c}+1}^{k}-\left(w_{1}\right)_{i, N_{c}}^{k}}{\Delta \xi}\right) \\
& +\mu\left(\xi_{N+1}\right)\left(\frac{\left(u_{2}\right)_{i+1, N+1}^{k}-\left(u_{2}\right)_{i-1, N+1}^{k}}{2 \Delta z}-\frac{1}{R_{i}^{k}}\left(\frac{\partial R}{\partial z}\right)_{i}^{k} \frac{\left(u_{2}\right)_{i, N+1}^{k}-\left(u_{2}\right)_{i, N}^{k}}{\Delta \xi^{\prime}}\right.
\end{aligned}
$$




$$
\left.+\frac{1}{R_{i}^{k}} \frac{\left(w_{2}\right)_{i, N+1}^{k}-\left(w_{2}\right)_{i, N}^{k}}{\Delta \xi^{\prime}}\right) .
$$

Finally, the expressions for the dimensionless flux $\left(Q^{\prime}\right)$, resistance to flow $\left(\lambda^{\prime}\right)$ and wall shear stress $\left(\tau^{\prime}\right)$ are given as

$$
{Q_{i}^{\prime}}^{k}=\frac{Q_{i}^{k}}{\left(Q_{n}\right)_{i}^{k}}, \quad \lambda_{i}^{\prime k}=\frac{\lambda_{i}^{k}}{\left(\lambda_{n}\right)_{i}^{k}}, \quad{\tau^{\prime}}_{i}^{k}=\frac{\tau_{i}^{k}}{\left(\tau_{n}\right)_{i}^{k}}
$$

where $Q_{n}, \lambda_{n}$ and $\tau_{n}$ are the flux, the resistance to flow and wall shear stress, respectively, for the normal artery in the absence of peripheral layer.

The major steps in the computation sequence may be summarized as follows:

1. Set the values of $u_{m}, w_{m} ; m=1,2$ in the entire field at $t_{0}=0$.

2. Calculate $\left(w_{2}\right)_{i, j}^{k+1}$ (i.e. at $t=t_{1}=t_{0}+\Delta t$ ) from equation (5.4) for $j=$ $N+1$ to $j=N_{c}+1$ i.e. from $\xi=1$ to $\xi=\alpha$ by exploiting appropriate boundary conditions.

3. Calculate $\left(w_{1}\right)_{i, N_{c}}^{k+1}$ from equation (5.7).

4. Calculate $\left(w_{1}\right)_{i, j}^{k+1}$ from equation (5.3) for $j=N_{c}-1$ to $j=1$ i.e. until $\xi=0$ is reached by exploiting appropriate boundary conditions

5. Calculate $\left(u_{2}\right)_{i, N_{c}+1}^{k+1}\left[=\left(u_{1}\right)_{i, N_{c}+1}^{k+1}\right]$ from equation (4.13) and put it into equations (4.11) and (4.12) and then calculate $\left(u_{1}\right)_{i, j}^{k+1}$ from equation (4.11) for $j=1$ to $j=N_{c}+1$ i.e. from $\xi=0$ to $\xi=\alpha$ using appropriate boundary conditions.

6. Calculate $\left(u_{2}\right)_{i, j}^{k+1}$ from equation (4.12) for $j=N_{c}+2$ to $j=n+1$ until $\xi=1$ is reached by using appropriate boundary conditions.

7. Computations for $t=t_{1}$ are continued until $z=L$ is reached.

8. Entire sequence is repeated for the next time increment and continued until desired time span has been achieved.

\section{NUMERICAL RESULTS AND DISCUSSION}

In this section we shall discuss the validity of the present updated model by undertaking a specific numerical illustration based on the existing experimental data for the various physiological parameters encountered in the present analysis. The viscosity of blood is chosen to be a function of hematocrit (Baker [2]) in the following form

$$
\mu(\xi)=\mu_{2}\left[1-k c_{v}(\xi)\right]^{-2.5},
$$


where $c_{v}(\xi)$ is the volume concentration of the red cells and is expressed as

$$
c_{v}(\xi)=c\left[1-\left(\frac{\xi}{\alpha}\right)^{q}\right] \theta(\alpha-\xi)
$$

and $\theta(\xi)$ is the Heaviside function defined by

$$
\theta(\xi)= \begin{cases}1, & \xi \geq 0 \\ 0, & \xi<0\end{cases}
$$

and $\mu_{2}$ being the plasma viscosity.

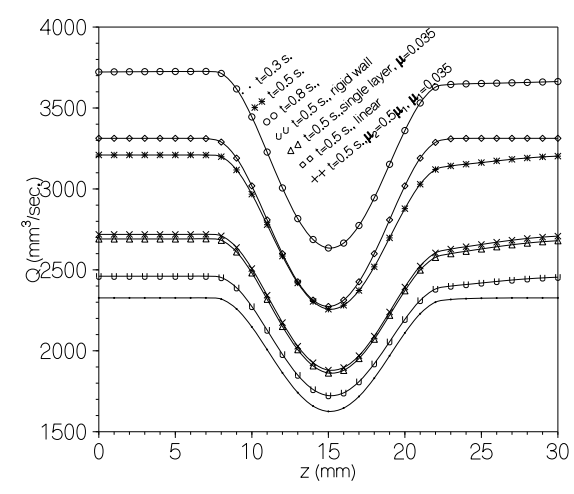

Figure 2. Distribution of the rate of flow for different time periods $\left(\tau_{m}=\right.$ $0.15 R_{0}, c=0.24, \mu_{2}=0.012$ ).

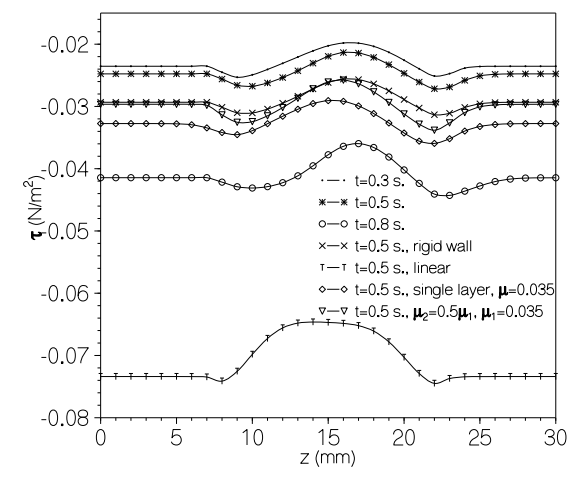

Figure 3. Distribution of the wall shear stress for different time periods $\left(\tau_{m}=\right.$ $0.15 R_{0}, c=0.24, \mu_{2}=0.012$ ).

For the purpose of numerical computations of the desired quantities of major physiological significance, the following parameter values have been useed (see, Thomas et al, [26]; Burton, [4]; Buliarello and Sevilla, [3]; Baker, [2]; Milnor, [15]; Sud and Sekhon, [25]):

$$
\begin{aligned}
& R_{0}=5 \mathrm{~mm}, L=30 \mathrm{~mm}, L_{0}=0.5 \mathrm{~L}, d=7.5 \mathrm{~mm}, b=0.1, \mu_{2}=0.012 P \\
& \rho=1.05 \times 10^{3} \mathrm{~kg} \cdot \mathrm{m}^{-3}, f_{p}=1.2 \mathrm{~Hz}, A_{0}=100 \mathrm{~kg} \cdot \mathrm{m}^{-2} \mathrm{~s}^{-2}, A_{1}=0.2 A_{0} \\
& \alpha=0.95, \tau_{m}=0.15 R_{0}, k=1.6, c=0.24, q=0.67, \Delta \xi=0.0125 \\
& \Delta \xi^{\prime}=0.0025, \Delta z=0.5
\end{aligned}
$$

The iterative method has been found to be quite effective in solving the equations (5.3) and (5.4) numerically for different time periods. The results 

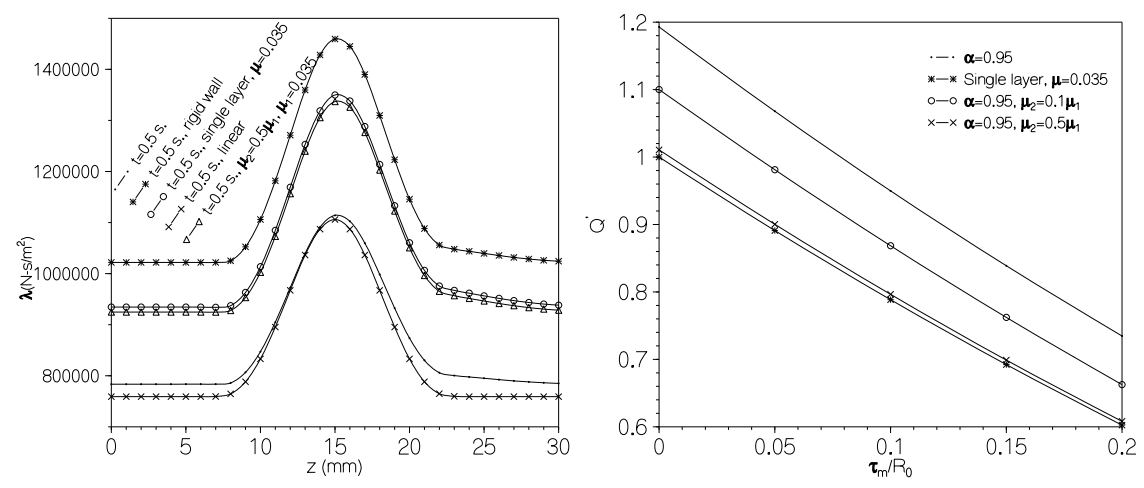

Figure 4. Distribution of resistance to flow for different time periods $\left(\tau_{m}=\right.$ $0.15 R_{0}, c=0.24, \mu_{2}=0.012$ ).

Figure 5. Distribution of dimensionless flow rate for $t=0.5 \mathrm{sec}$. at $z=15 \mathrm{~mm}(c=$ $0.24, \mu_{1}=0.035, \frac{L_{0}}{L}=0.5$ ).

appeared to converge with an accuracy of the order $\sim 10^{-6}$ when the time step was chosen to be 0.00001 .

The computed results obtained following the above mentioned method for various physical quantities of major physiological significance in order to have their quantitative measures are all exhibited through the Fig. $2-7$ and discussed at length.

The results of the present analysis are compared with (i) those of singlelayered Newtonian fluid ( $\mu_{2}=0.035, c=0$ ), (ii) the results of the two-layered model case of Newtonian fluid $\left(\mu_{1}=0.035, \frac{\mu_{2}}{\mu_{1}}=0.1,0.5\right)$, (iii) those for the rigid wall i.e. by disregarding the term $\frac{\partial R}{\partial t}$ in the governing equations and by treating $R=R(z)$ only and (iv) those for a linear model i.e. by discarding the convective acceleration terms in Navier-Stokes equations.

Fig. 2 exhibits the distribution of the flow rate over the stenosed arterial segment for three different time periods. The flow rate curves following the outline of the stenosis appear to diminish at the onset of the stenosis until the maximum constriction site and thereafter increase downstream symmetrically along the diverging section of the stenosis, that is, the flow rate curves become perfectly symmetrical about the critical location $(z=15 \mathrm{~mm})$ of maximum narrowing only in the constricted regions for all times. However, it assumes relatively higher unperturbed values in the non constricted portions of the artery. Moreover, the fact that the flow rate is reduced considerably in the absence of any arterial wall motion helps in establishing the importance of the consideration of the vessel wall deformability in the present model under study. It may be recorded that if the flowing blood is treated to be a single-layered Newtonian fluid $\left(\mu_{2}=0.035, c=0\right)$, the rate of flow is reduced 


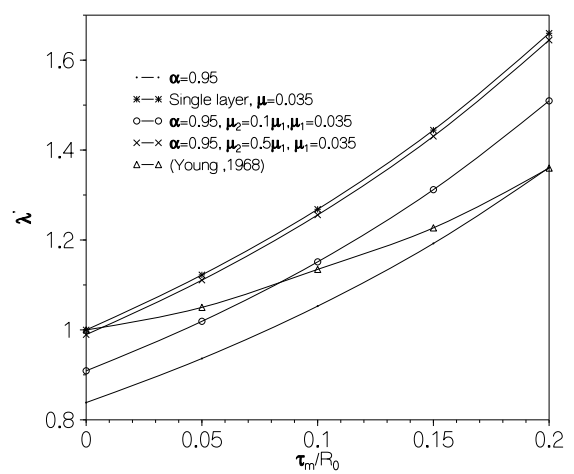

Figure 6. Distribution of dimensionless resistance to flow for $t=0.5$ sec. at $z=15$ $\mathrm{mm}\left(c=0.24, \mu_{1}=0.035, \frac{L_{0}}{L}=0.5\right)$.

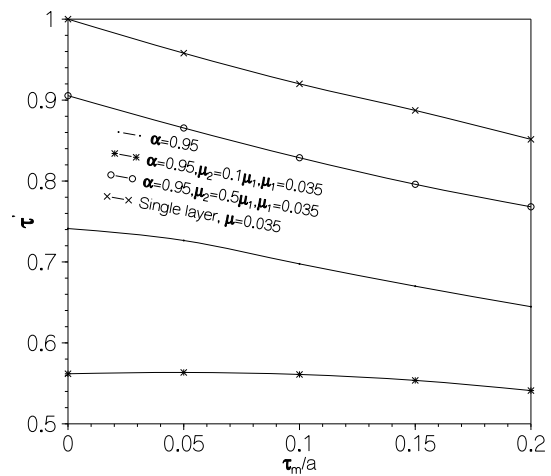

Figure 7. Distribution of dimensionless wall shear stress for $t=0.5 \mathrm{sec}$. at $z=15$ $\mathrm{mm}\left(c=0.24, \mu_{1}=0.035, \frac{L_{0}}{L}=0.5\right)$.

considerably which can be easily estimated by comparing the relevant curves with distinguishable marks. One can also notice the behaviour of the flow rate for a linear model where the flux distribution keeps on increasing in the non-stenotic region. The present figure also includes the corresponding results based on two-layered Newtonian model $\left(\mu_{1}=0.035, \frac{\mu_{2}}{\mu_{1}}=0.5\right)$, and the effects of red cell concentration and the peripheral layer viscosity can be quantified through a numerical comparison between the relevant curves. It is worth mentioning that the flow rate enhances or reduces to some extent with the arterial length confined to the stenotic region only depending upon whether the arterial cross section increases or decreases respectively.

The results of the wall shear stress distributed over the entire stenosed arterial segment for different time periods are displayed in Fig. 3. The stresses appear to be compressive in nature throughout the artery which become maximum only at the critical location where the artery assumes its constriction maximum. The nonstenotic portions are however slightly perturbed with relatively lower stress values. Beside this, if one disregards the vessel wall distensibility, the stresses are noted to increase considerably like those for a single-layered Newtonian fluid $(\mu=0.035, c=0)$, two-layered Newtonian fluid $\left(\mu_{1}=0.035, \frac{\mu_{2}}{\mu_{1}}=0.5\right)$ and for a linear model so far as their magnitudes are concerned. Thus the effects of red cell concentration, the wall flexibility, the nonlinearity and the red cell concentration on the wall shear stress over the arterial length can be quantified through the direct comparison of the relevant curves. The present figure also exhibits that as time progresses from $t=0.5 \mathrm{~s}$. to $t=0.8 \mathrm{~s}$, , the symmetric characteristic of the stress distribution is slightly disturbed but with appreciable deviation of magnitudes. The present stress 
distribution is believed to play an important role in detecting the aggregation sites of platelets as remarked in Fry [11] that the growth and deterioration of the endothelial cells of the arterial wall are closely connected to the generation of shear stress on the arterial wall.

Fig. 4 indicates how the resistive impedances are influenced by the unsteady flow behaviour of blood as well as by the vessel wall distensibility, the flow nonlinearity and by the peripheral layer viscosity. The resistive impedances, unlike the characteristics of the flow rate, start increasing at the onset of the stenosis from relatively lower unperturbed values in the nonconstricted portion until its maximum constriction followed by a symmetrical decline downstream as the constriction approaches its minimum and then they become invariant outside the stenotic region. One may observe that the flowing blood experiences much higher resistances to flow in the absence of vessel wall distensibility, in the absence of peripheral layer (single layer) and also in case of two-layered Newtonian model but a complete reverse phenomenon is observed in case of linear model and consequently the effect of wall distensibility, the peripheral layer, the inhomogeneity and the nonlinearity on the resistive impedances can be measured quantitatively through a direct comparison of the curves corresponding to the same instant of $t=0.5 \mathrm{~s}$.

For the sake of undertaking a comparative study with the existing ones in order to substantiate the validity of the present theoretical analysis, some critical results for $Q^{\prime}, \lambda^{\prime}$ and $\tau^{\prime}$ (vs. stenosis size $\frac{\tau_{m}}{R_{0}}$ ) have been plotted in Fig. $5-7$.

Fig. 5 shows the distribution of dimensionless flow rate $\left(Q^{\prime}\right)$ at the maximum narrowing of the arterial lumen $(z=15 \mathrm{~mm})$ at $t=0.5 \mathrm{sec}$. with stenosis size $\frac{\tau_{m}}{R_{0}}$. For the fixed stenosis size, $Q^{\prime}$ decreases if the flowing blood can be treated as homogeneous and increases as the peripheral layer viscosity decreases. If the flowing blood can be treated as a single layer fluid $(\mu=0.035, c=0)$, the dimensionless flux is found to be decreasing compared to all the curves as depicted in Fig. 5. In addition, it may be noted from the present figure that in all the cases $Q^{\prime}$ decreases as the size of the stenosis increases for a given set of parameters.

The plots of Fig. 6 indicate the effect of inhomogeneity and peripheral layer viscosity on the distribution of the dimensionless resistive impedances $\left(\lambda^{\prime}\right)$ with stenosis size $\frac{\tau_{m}}{R_{0}}$ at a specific time of $t=0.5 \mathrm{sec}$. at the site where the arterial constriction gets maximum $(z=15 \mathrm{~mm})$. One may notice that the resistance to flow increases in magnitude to a considerable extent with increasing stenosis size from 0 to 0.2 . It may also be noted that the magnitudes of the resistance to flow, under given set of conditions decreases with the decrease of the peripheral layer viscosity and if the flowing blood can be treated as a single layered Newtonian fluid, the resistance to flow, $\lambda^{\prime}$, increases compared to two-layered Newtonian fluid and two-layered inhomogeneous Newtonian fluid. These results agree well with those of Shukla et al [21] who studied the twolayered one dimensional model of Newtonian fluid and also support Srivastava and Saxena [24] qualitatively well who studied two-layered one dimensional 
model of blood flow consisting of a core region assumed to be Casson fluid and a peripheral layer of plasma as a Newtonian fluid. Moreover, a comparison has also been made with the existing result of Young [10] who studied the one-dimensional model of blood flow in the absence of peripheral layer. A considerable deviation of the results thus obtained from the second and the fifth curves may be due to the additional considerations of unsteadiness, nonlinearity, vessel wall distensibility and also two-dimensional flow as encountered in the present improved model.

Finally, the concluding Fig. 7 of the present paper illustrates the effects of the peripheral layer viscosity, the inhomogeneity of the streaming blood on the dimensionless wall shear stress $\left(\tau^{\prime}\right)$ plotted with stenosis size $\frac{\tau_{m}}{R_{0}}$ at a specific time of $t=0.5 \mathrm{sec}$. at the maximum constriction site $(z=15 \mathrm{~mm})$ of the artery. The notable feature is that the stress is compressive in nature and hence the downward trend of the curves indicates the enhancement of the stress due to the increase of the severity of the stenosis for all cases. This, in turn, can be stated as - the more the severity of the stenosis, the more the wall shear stress. Again, it can be easily estimated that as the viscosity of the peripheral layer increases, the dimensionless wall shear stress increases if one follows through the relevant curves of the present figure. Moreover, if the flowing blood is treated to be single-layered Newtonian fluid, the stress is found to be all time higher than those for the two-layered Newtonian and two-layered inhomogeneous Newtonian models. These features once again are in good agreement with those of Shukla et al [21] and Srivastava and Saxena [24] whose studies were based on one-dimensional model of blood flow in rigid arteries only.

The significance of the consideration of any improved mathematical model such as the present one can now be completely understood from the above mentioned discussion. Studying the present quantitative analysis together with our previous results [cf. Chakravarty et al [6], it may be remarked that the resistance to flow and the wall shear stress decrease in the case of two layered model compared to the single layered model and therefore one can conclude that the presence of peripheral plasma is of major physiological significance regarding the functioning of the diseased arterial system. These observations agree qualitatively well with those of Shukla et al [21] and Srivastava and Saxena [24] and hence the applicability of the present model is well validated.

\section{REFERENCES}

[1] H.I. Anderson, R. Halden and T. Glomsaker. Effect of surface irregularities on flow resistance in differently shaped arterial stenoses. J. Biomech., 33, $1257-1262,2000$.

[2] M. Baker. Double-Slit Photometric Measurement of Velocity Profiles for Blood in Microvessels and Capillary Tubes, Ph. D. Thesis. Pasadena, California, Institute of Technology, 1972.

[3] G. Bugliarello and J. Sevilla. Velocity distribution and other characteristics of steady and pulsatile blood flow in fine glass tubes. Biorheology, 7, 85-107, 1970. 
[4] A. C. Burton. Physiology and Biophysics of the Circulation, Introductory Text. Year Book Medical Publisher, Chicago, 1966.

[5] S. Chakravarty and A. Datta. Dynamic response of stenotic blood flow in vivo. Math. Comp. Modelling, 16, 3 - 20, 1992.

[6] S. Chakravarty, A. Datta and P. K. Mandal. Analysis of nonlinear blood flow in a stenosed flexible artery. Int. J. Engng. Sci., 33, $1821-1837,1995$.

[7] S. Chakravarty and P. K. Mandal. Two-dimensional blood flow through tapered arties under stenotic conditions. Int. J. Nonlinear. Mech., 35, $779-793,2000$.

[8] P. Chaturani and R.P. Samy. Pulsatile flow of casson's fluid through stenosed arteries with applications to blood flow. Biorheology, 23, $499-511,1986$.

[9] E. Deplano and M. Siouffi. Experimental and numerical study of pulsatile flow through stenosis: wall shear stress analysis. J. Biomech., 32, 1081 - 1090, 1999.

[10] Young. D. F. Effects of a time-dependent stenosis of flow through a tube. Engng. Ind., 90, $248-254,1968$.

[11] D. L. Fry. Acute vascular endothelial changes associated with increased blood velocity gradients. Circulation Res., 22, 165 - 197, 1968.

[12] K. Imaeda and F. O. Goodman. Analysis of nonlinear pulsatile blood flow in arteries. Biomech., 13, 1007 - 1022, 1980.

[13] D. Liepsch, Pflugbeil G., Matsuo T. and Lesnaik B. Flow visualization and 1- and 3-D laser-Doppler-anemometer measurement in models of human carotid arteries. Clinical Hemorhelogy, 1, 1 - 30, 1998.

[14] Q. Long, X.Y. Ku, K.V. Ramnarine and P. Hoskins. Numerical investigation of physiologically realistic pulsatile flow through arteries stenosis. J. Biomech., 34, $1229-1242$, 2001.

[15] W. R. Milnor. Hemodynamics. Baltimore, 1982.

[16] J. C. Misra and S. Chakravarty. Flow in arteries in the presence of stenosis. Biomech., 19, $907-918,1986$.

[17] J. C. Misra, M.K. Patra and S.C. Misra. A non-Newtonian fluid model for blood flow through arteries under stenotic conditions. Biomech., 26, 1129 - 1141, 1993.

[18] M. Nakamura and T. Swada. Numerical study on the unsteady flow on non-Newtonian fluid. Biomech., 112, $100-103,1990$.

[19] J. Pedley, T. The fluid mechanics of large blood vessels. Cambridge University Press, London, 1980.

[20] R. N. Pralhad and D. H. Schultz. Two-layered blood flow through stenosed tubes for different diseases. Biorheology, 25, $715-726,1988$.

[21] J. B. Shukla, R. S. Parihar and B. R. P. Rao. Effects of peripheral layer viscosity on blood flow through the artery with mild stenosis. Bull. Math. Biol., 42, $797-805$, 1980.

[22] L. M. Srivastava. Flow of couple stress fluid through stenotic blood vessels. Biomech., 18, $479-485,1985$.

[23] V. P. Srivastava. Two-phase model of blood flow through stenosed tubes in the presence of a peripheral layer: Applications. Biomech., 29, 1377 - 1382, 1996.

[24] V. P. Srivastava and M Saxena. Two-layered model of Casson fluid flow through stenotic blood vessels: applications to the cardiovascular system. Biomech., 27, 921 928, 1994.

[25] V. K. Sud and G. S. Sekhon. Arterial flow under periodic body acceleration. Bull. Math. Biol., 47, $35-52,1985$.

[26] H. W. Thomas, R. J. French, A. C. Groom and S. Rowlands. The flow of red cell suspensions through narrow tubes. In: Proc. IVth. Int. Cong. Rheology, volume 4 of Interscience, New York, 381 - 391, 1965. 
[27] G. B. Thurston. Plasma release-cell layering theory for blood flow. Biorheology, 26, $199-214,1989$.

[28] C. Tu and M. Deville. Pulsatile flow in non-Newtonian fluid through arterial stenosis. J. Biomech., 29, 899 - 908, 1996.

\section{Netiesinio dviejų sluoksnių dvimačio modelio analizę}

P. Mandal

Straipsnyje ištirti raudonujų kraujo kūneliu koncentracijos efektai ir periferinio sluoksnio klampumas priklausomai nuo pulsavimo fiziologiniu charakteristiku, esant nestipriai stenozei. Tekantis kraujas aprašomas dvieju skysčiu modeliu, vienas iš jų laikomas neniutoniniu skysčiu, kitas - periferinè plazma, laikoma niutoniniu skysčiu be jokių ląstelių. Kraujo srauto klampumas yra hematokrito funkcija, kuri keičiasi pagal spinduli neniutoniniame skystyje, o plazmoje nekinta. I modelio tyrimą itraukti arterijų sieneliu judejimas ir jo sukelti efektai lokaliajai skysčio mechanikai. Baigtinių skirtumų schema naudojama spręsti nestacionarias Navier-Stokes lygtis cilindrinèse koordinatèse, kai laminarinès sąlygos tenkina ašinio simetriškumo sąlygą, ir uždavinys yra faktiškai dvimatis. Pateiktas skaitinis eksperimentas patvirtina modelio tinkamumą. 